\title{
Possibilities for the use of Anatomage (the Anatomical Real Body-Size Table) for Teaching and Learning Anatomy with the Students
}

\author{
Jesús García Martín*, Concepción Dankloff Mora and Soledad Aguado Henche \\ Department of Surgery and Social and Medical Sciences, Unit of Human Anatomy and Embryology, Faculty of Medicine and Health Sciences. University of \\ Alcalá. Alcalá de Henares. 28871 - Madrid, Spain
}

Received: May 11,2018; Published: May 21, 2018

*Corresponding author: Jesús García Martín, Department of Surgery and Social and Medical Sciences, Unit of Human Anatomy and Embryology, Professor of Human Anatomy and Embryology, Faculty of Medicine and Health Sciences, University of Alcalá, Alcalá de Henares, 28871 - Madrid, Spain

\begin{abstract}
The purpose of this article was to describe and explain our experience with Anatomage table in the process of teaching and learning anatomy to medicine students who are preparing as military physicians. Anatomage combines stereoscopic images of the whole body with software in order to build a 3-dimensional (3-D) reconstruction of the different human body parts. These images were taken from two cadavers, male and female, who were frozen and cut into sections to allow for virtual dissection and reconstruction of the human body. Users can visualize anatomy exactly as they would on a fresh cadaver. The table allows for exploration and learning of human anatomy beyond the experience with a cadaver. It is possible to cut away from the body surface to the inner body using a scalpel, as well as to watch images of 3-D sections in the three spatial planes.We described the importance of dissection in practical anatomy teaching, and the large number of body donations needed. Thus, many authors have proposed different solutions, such as software with reconstructions of the human body. Anatomage allows for anatomy teaching and learning in an interactive way. Students can practice actively and take the images watched in a practical session with them in a storage device, in order to study and discuss them later in a lecture. Anatomage is also used for practical anatomy exams to students. Despite being rather costly, it stimulates the learning of anatomy by being directly used by students in various ways.
\end{abstract}

Keywords: Anatomy Education; Dissection; Anatomical Software; Anatomage

\section{Introduction}

Traditionally, anatomy teaching and learning were focused on dissection, which can be directly performed by students or guided by professors [1]. This is an important subject in medical schools' curriculum and it is considered essential by many authors, such as Turney [2]. However, new and more interactive ways of teaching anatomy have gained importance to help students and professors learn and teach the human body structure [3]. Several of these techniques include anatomical software, as the Zygote [4]. One of the most important parts of future physicians' curriculum is preparation for surgery and this must include the knowledge of anatomy. One of the most usual techniques to acquire these skills is dissection. Dissection is the exposure and description of internal body organs and structures [5]. To achieve this goal, a large number of bodies need to be donated and perfectly fixed.

To reduce these needs and make anatomy teaching and learning easier, other techniques have been developed. One of these techniques is cross-sectional human anatomy, widely developed during the nineteenth century by anatomists such as Pirogoff and Braune, who published an atlas with figures in the three spatial planes (sagittal, coronal and transverse) of frozen cadavers sectioned with a band saw [6]. It was the precursor of harmless techniques developed in the last decades that allow us to know about our inner organs and structures. These techniques are called Computed Tomography (CT) [7] and Magnetic Resonance Imaging (MRI) [8]. Recently, a computerized body-size table has been designed combining CT scan, X-Ray, ultrasound and MRI, stereoscopic images of the different human body parts with software in order to build a 3-dimensional (3-D) reconstruction of the whole body. It is ANATOMAGE [9], a computerized table developed by a 3-D medical technology company located in San José (California) in conjunction with Stanford University's Clinical Anatomy Division. This technology allows for virtual dissection and reconstruction of the 
human body. By means of a fully interactive multitouch screen, one can dissect the body, moving through layers of tissue or use a virtual knife to cut away and see the structures inside [10]. There is one Anatomage table at the Defense University Center (Centro Universitario de la Defensa) in Madrid (Spain). This new technology allows professors to teach anatomy to students in an interactive way (Figure 1).

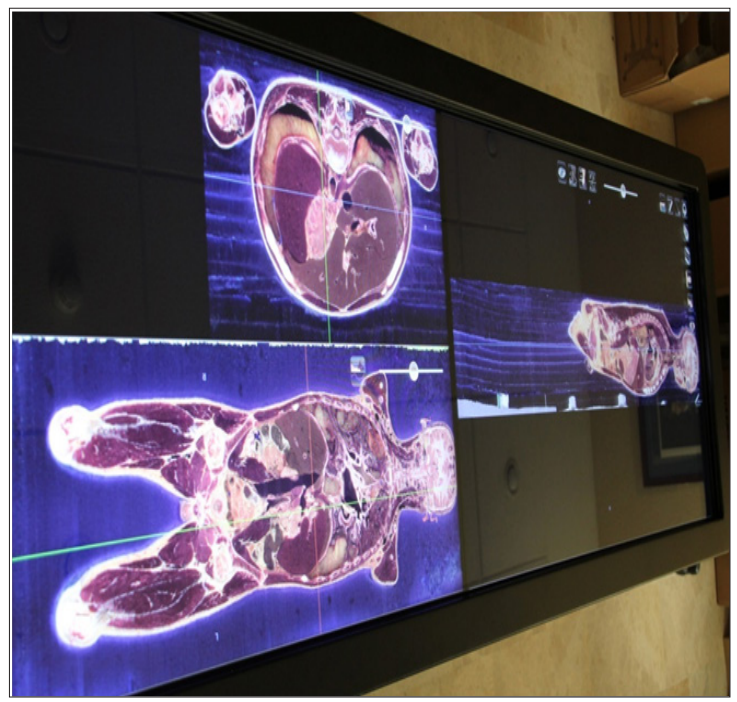

Figure 1: Liver sections in the three spatial planes.

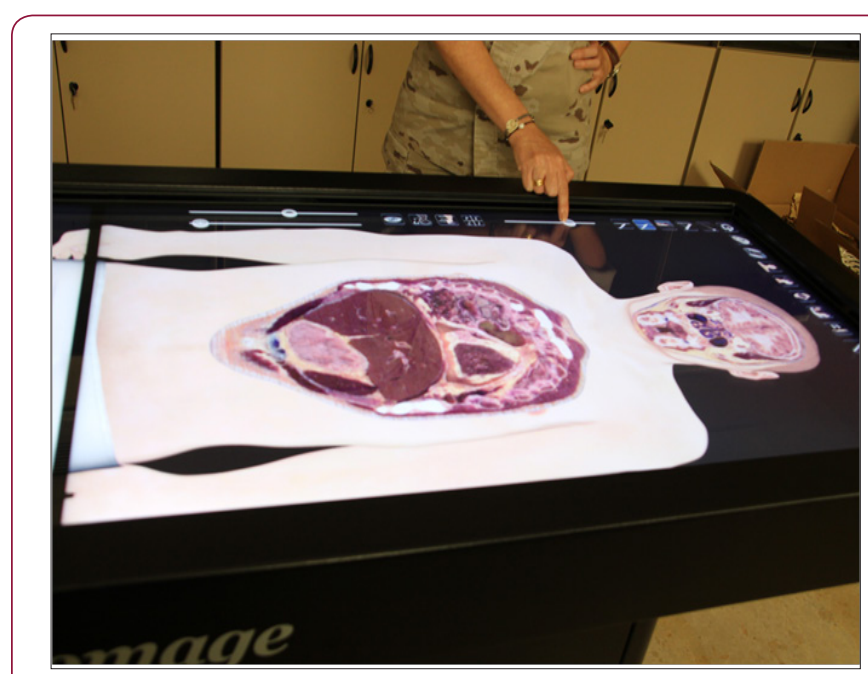

Figure 2: Progression in the inner views of different levels of sections.

\section{Traditional Anatomy Teaching}

The most common way to teach anatomy in a practical way has been dissection, which is the exposure and description of internal body organs and structures. It consists in dismembering the body of a deceased human to study the anatomical structure and it is typically conducted in an anatomy lab [11]. The dissection laboratory provides an environment in which the senses of touch and vision can be used to enhance the understanding of the human body. Students can truly see and feel structures that lie under the skin, e.g. nerves, veins and arteries [12]. Although the number of laboratory hours in gross anatomy courses has decreased in most medical schools, the dissection laboratory continues to be a learning environment in which students of anatomy gain a 3-dimensional perspective of the relationships among different parts of the internal human body. Another option is the prosection, where a "prepared" specimen is preserved in a solution and pre-dissected by an experienced anatomist. Students follow the guidance and indications of the anatomist and study the parts and structures that are contained in a specific region of the human body [2] (Figure 2).

\section{Solutions and Alternatives}

Anatomical models are used in all medical schools to teach human anatomy to students. Other options are to use anatomical software like Zygote [4] or Visiblebody.com, which contains a 3-D atlas of anatomical models [13]. One important contribution to the advance of knowledge and understanding of the human body internal structure was cross-sectional anatomy. One of the most renowned atlases that show this technique is Color Atlas of Anatomy. A photographic study of the human body by Rohen Yokochi and Lütjen-Drecoll [14] Other important authors like Kim EE, et al. [15] and Moeller and Reif [16] designed atlases based on cross-sectional anatomy. They used high-quality photographs to detail side-to-side anatomical cross sections and their corresponding CT and MRI images to clarify their location and structure. This was an important step to the next advance, the 3-dimensional reconstruction of the human body internal structures.

\section{A computerized Body-Size Table}

\section{Anatomage}

Anatomage table is a technologically advanced anatomy visualization system for anatomy education and it is being adopted by many of the world's leading medical schools and institutions [10]. Anatomage combines stereoscopic images of the whole body with software in order to build a 3-D reconstruction of the different human body parts (taken initially from two cadavers: male and female) that allows for virtual dissection and reconstruction. This computerized body-size table features a 7 by 2.5 -foot screen and combines the technology of CT scan, X-Ray, ultrasound and MRI to reconstruct the human body [9]. Anatomage table is a fully segmented real human 3-D anatomy system. The use of virtual dissection technology seems to have a promising role in future educational training although more research is needed to better understand the efficacy of using this technology in the classroom. In this regard, Custer and Michael concluded that students appreciate learning with this technology and believe that it is a beneficial and effective tool in preparing them to enter a health care profession [17].

Anatomage table-based education has proven to be effective. An increasing number of publications show improved test scores, more efficient classroom and lab sessions, and student acceptance. The accurate details and rich content draw students' interest and attention, leading to more effective educational outcomes [10]. The incorporation of cadaver CT scans and life-size virtual dissection tables significantly improved the performance of medical students in general gross anatomy. Medical imaging and virtual dissection 
should therefore be considered to be part of the standard curriculum of gross anatomy $[18,19]$.

Anatomage presents some noteworthy advantages compared with the use of cadavers. Embalming products or a special place for the anatomical table is not necessary. There are no restrictions and permits are not required to use it. The number of cases is almost unlimited and recurring costs are minimal, since it is not necessary to replace the cadavers every year. The anatomical accuracy in the reconstruction of the human body is very high, since it is based on real human bodies. It is also possible to cut and make sections of the body in any direction [20]. Despite Anatomage being rather costly, it can be used frequently and for a long period of time. Typically, its most usual application is dissection replacement. With a fully interactive, multitouch screen, it is possible to dissect the body, moving through layers of tissues or using a virtual knife to cut away and see the structures inside [19, 21-23].

Anatomage table also offers the option to combine scanning planes to get a better understanding of the location and relationships of the different human body inner structures. It is possible to combine the view at one level with the view of structures in the three spatial planes (sagittal and parasagittal, coronal and transverse), and to move up and down to check the structures at different levels of cross section. This allows the user to watch a complete and perfect 3-D view of the size, position and relationships of organs, vessels, nerves, muscles and spaces inside our body [21].

\section{Conclusion}

In our experience, Anatomage is a highly motivating way to learn anatomy by students. We have the advantage of having a short number of students (around 30 in total, dividing them in smaller groups). We orientate the study providing short guides of each anatomical region and we ask directly them or they can ask each other. They show great interest to improve and enhance their knowledge. The chance to check again the anatomical sections or the different organs and structures to make corrections, using the help of the names written on Anatomage screen is highly appreciated by students. We also use the Anatomage for evaluation purposes.

\section{Acknowledgement}

Natalio García Honduvilla, Ph.D. Department of Biomedical Sciences, Professor of Histology and Director of the Defense University Center (Centro Universitario de la Defensa) in Madrid, Faculty of Medicine and Health Sciences, University of AlcaláAlcalá de Henares, 28871 - Madrid, SPAIN, For giving me the opportunity to develop a practical and research work with the students of medicine and the use of Anatomage.

María Asunción Sánchez Gil, M.D. Medical Lieutenant Colonel, Secretary of the Defense University Center (Centro Universitario de la Defensa) in Madrid, Faculty of Medicine and Health Sciences, University of AlcaláAlcalá de Henares, 28871 - Madrid, SPAIN, For her essential and invaluable help to collect all the audiovisual material (pictures and videos) from Anatomage table.

\section{References}

1. Johnson JH (2002) Importance of dissection in learning anatomy: personal dissetion versus peer teaching. Clin. Anat 15(1): 38-44.

2. Turney BW (2007) Anatomy in a Modern Medical Curriculum. Ann R Coll Surg Engl Mar 89(2): 104-107.

3. Standring S (2008) Gray's Anatomy Gray's anatomy: the anatomical basis of clinical practice. ( $40^{\text {th }}$ Edn.). London: Churchill Livingstone, UK.

4. Astrachan M (2018) Creative Director from the Zygote.

5. McLachlan JC, Patten D (2006) Anatomy teaching: ghosts of the past, present and future. Medical Education 40: 243-253.

6. D’Alessandro MP, Bergman RA (1995-2018) Anatomy Atlases. An Anatomy Digital Library.

7. Hounsfield GN (1979) Computed medical imaging. Nobel lecture.

8. Martin GE, Zekter AS (1988) Two-Dimensional NMR Methods for Establishing Molecular Connectivity. N York, USA.

9. Ruiz V (2013) The Anatomage table - Visualizing Life Size Anatomy.

10. (2018) Anatomage Table.

11. Ghosh, Sanjib K (2015) Human cadaveric dissection: a historical account from ancient Greece to the modern era. Anatomy \& Cell Biology 48 (3): 153-169.

12. Winkelman A (2007) Anatomical dissection as a teaching method in medical school: a review of the evidence. Medical Education. Wiley Online Library, Gemany.

13. Eason, Martin P (2013) Anatomical dissection as a teaching method in medical school: a review of the evidence. The use of simulation in teaching the basic sciences. Curr Opinion Anesthes 26(6): 721-725.

14. Rohen JW, Yokochi C, Lütjen-Drecoll E (2015) Color atlas of anatomy (7 $7^{\text {th }}$ Edn.). Wolters Kluwer Health, USA.

15. Kim EE, Mar MV, Inoue T, Chung JK (2007) Sectional Anatomy: PET/CT and SPECT/CT. Springer, USA.

16. Moeller TB, Reif E (2007) Pocket altas of sectional anatomy - Computed tomography and magnetic resonance imaging 2 . Thorax, heart, abdomen, and pelvis. 3rd. Rev. Thieme Flexibook. Stuttgart Germany, p. 255.

17. Custer TM, Michael K (2015) The Utilization of the Anatomage Virtual Dissection Table in the Education of Imaging Science Students. J Tomogr Simul 1:1-5.

18. Paech D, Giesel FL, Unterhinninghofen R, Schlemmer HP, Kuner T, Doll S (2017) Cadaver-specific CT scans visualized at the dissection table combined with virtual dissection tables improve learning performance in general gross anatomy. Eur Radiol 27(5): 2153-2160.

19. Duparc F (2017) 3d-Virtual Dissection Table: We did not imagine how much it will be useful for teaching anatomy and clinical anatomy. Rev Arg Anat Clin 9(1): 9-10.

20. Fredieu JR, Kerbo J, Herron M, Klatte R, Cooke M (2015) Anatomical Models: a Digital Revolution. Medical Science Educator 25(2): 183-194.

21. Fyfe G, Fyfe S, Dye D, Radley-Crabb H (2013) Use of Anatomage tables in a large first year core unit. In Carter H, Gosper M and Hedberg J (Eds.), Proceedings of the Electric Dreams 30 ${ }^{\text {th }}$ Conference: 298-302.

22. (2018) Anatomage In vivo 6.

23. Smith MC, Holmes T (2018) SWS Clinical Skills and Simulation, Anatomage Table. UNSW Sydney, Australia. 
(c) (P) This work is licensed under Creative Submission Link: https://biomedres.us/submit-manuscript.php

AIOMEDICAL
RESEARCHES $\quad \begin{aligned} & \text { Assets of Publishing with us } \\ & \text { - Global archiving of articles }\end{aligned}$

